\title{
Continuity of airway goblet cells and intraluminal mucus in the airways of patients with bronchial asthma
}

\author{
S. Shimura, Y. Andoh, M. Haraguchi, K. Shirato
}

Continuity of airway goblet cells and intraluminal mucus in the airways of patients with bronchial asthma. S. Shimura, Y. Andoh, M. Haraguchi, K. Shirato. @ERS Journals Ltd 1996.

ABSTRACT: The aim of this study was to elucidate the mechanism of the formation of the widespread mucous-plugging observed in autopsied lungs from patients with bronchial asthma.

We performed morphometric analysis of airways of autopsied lungs from eight patients with bronchial asthma (Group BA), and compared it with those of six chronic bronchitics (Group CB) and four control patients (Control). The following parameters were measured in paraffin sections: volume proportion of bronchial glands to bronchial wall (Gland\%); goblet cell granules to total epithelial layer (Goblet\%); intraluminal mucus expressed as the mucus occupying ratio (MOR); volume ratio of intraluminal mucus continuous with goblet cells to total intraluminal mucus $(V \mathrm{c} / V$ tot $\%)$; and surface ratio of the contact surface of intraluminal mucus continuous with goblet cells to the total luminal surface $(\mathrm{Sc} / \mathrm{Stot} \%)$.

Gland\%, Goblet\%, and MOR or inflammatory cell numbers in the airway walls both from Group BA and CB were larger than those from the Control group. However, no significant differences were observed between Group BA and CB in Gland\%, Goblet\%, MOR or inflammatory cell numbers, except for the eosinophil number: i.e. $23 \pm 3,22 \pm 3$ and $6 \pm 2 \%$ in Gland\%; $22 \pm 9,5 \pm 4$ and $2 \pm 2 \%$ in Goblet $\%$; $10 \pm 3,18 \pm 3$ and $0.3 \pm 0.5 \%$ in MOR; $199 \pm 68,10 \pm 3$ and $2 \pm 2$ cells $\mathrm{mm}^{-2}$ in eosinophil number of the peripheral airways from Groups BA, CB and Control, respectively. In contrast, marked and significant increases were observed both in $V_{\mathrm{c}} / V$ tot $\%$ and $\mathrm{Sc} / \mathrm{Stot} \%$ in Group BA compared to Groups $\mathrm{CB}$ and Control both in central and peripheral airways: i.e. $V \mathrm{c} / V$ tot $\%$ in the peripheral airways was $53 \pm 5,4 \pm 3$ and $0.8 \pm 0.8 \%$ from Groups BA, CB and Control, respectively (BA vs CB or BA vs Control, $\mathrm{p}<0.01$ each).

These findings suggest that the continuity of goblet cells and intraluminal mucus or lack of full release of mucus, from goblet cells, is peculiar to asthmatic airways, and may contribute to the formation of mucous-plugs.

Eur Respir J., 1996, 9, 1395-1401.
First Dept of Internal Medicine, Tohoku University School of Medicine, Sendai, Japan.

\section{Correspondence: S. Shimura}

First Dept of Internal Medicine

Tohoku University School of Medicine

1-1 Seiryo-machi

Aoba-ku

Sendai 980-77

Japan

Keywords: Bronchial asthma goblet cell hyperplasia

intraluminal mucus accumulation mucous-plugging

Received: September 71995

Accepted after revision March 161996
It is possible that, in addition to bronchoconstriction and mucosal oedema, mucous plugs contribute to airway obstruction and death in bronchial asthma, since large amounts of mucous-plugging are observed in airways in the autopsied lungs of patients with bronchial asthma [1-3]. For example, SAETTA et al. [4] have reported that asthmatic patients who died suddenly and unexpectedly showed occlusion of the lumen by mucous plugs, plasma exudate and inflammatory cells in the peripheral airways of autopsied lungs. Airway glandular hyperplasia, goblet cell hyperplasia and/or hypertrophy are pathological characteristics of bronchial asthma similar to those observed in chronic bronchitis [5, 6]. It is also known that a significant amount of intraluminal mucus is present in the airways of patients with chronic bronchitis, to a degree similar to those of patients with bronchial asthma [7]. However, Cosio et al. [8] found that mucus and cells in the lumen of peripheral airways from surgical specimens were of no definite significance with respect to pulmonary function in chronic obstructive pulmonary disease.
Thus, the significance of intraluminal mucus in the airways seems to be different in bronchial asthma and chronic bronchitis. However, it is uncertain whether there are any differences in luminal mucus or mucous-plugging between bronchial asthma and chronic bronchitis.

There have been no reports of a morphometric comparison of intraluminal mucus in the airways of patients with bronchial asthma and chronic bronchitis, with particular reference to the formation of mucous-plugging. From autopsied lungs, we have noted that the continuity of goblet cells intracellular mucus and airway mucus seems to be more prevalent in bronchial asthma, compared to the airways from chronic bronchitics. In the present study, therefore, we used morphometric techniques to analyse intraluminal mucus from the autopsied lungs of patients with bronchial asthma, and compared it with those from patients with chronic bronchitis, in order to obtain novel information concerning the formation of mucous-plugging in the airways of patients with bronchial asthma. 


\section{Methods}

\section{Subjects}

Autopsied lungs from eight patients with bronchial asthma (Group BA), six patients with chronic bronchitis (Group CB) and four control patients (Control) were obtained after consulting the medical records over the past 10 yrs at Tohoku University Hospital, National Sendai General Hospital and Hiraga General Hospital. Clinical and laboratory data from the patients are shown in table 1. Control lungs were obtained from four patients who died of nonrespiratory diseases and all were clinically free of respiratory diseases (table 1). Diagnosis of bronchial asthma and chronic bronchitis was in accordance with the definition of the American Thoracic Society (ATS) committee [9]. The patients with bronchial asthma were all of the intrinsic type, as defined by RACKEMANN [10].

Group BA included three out-patients who arrived at the hospital in status asthmaticus and died 3-8 h after the onset of the last asthma attack in spite of intensive care (BA Nos. 1-3 in table 1) (subgroup BA-I). The other five patients in Group BA had been in the hospital 1-6 months for treatment of chronic severe asthma and had died of chronic respiratory failure, sepsis, systemic cytomegalovirus infection or pulmonary embolism (BA Nos.
4-8 in table 1) (subgroup BA-II). All patients with chronic bronchitis were defined as having chronic obstructive mucopurulent bronchitis according to the British Medical Research Council definition of chronic bronchitis [11], and also had diffuse panbronchiolitis as described by Номма et al. [12]. Patients with chronic bronchitis had chronic sputum production $\left(>10 \mathrm{~mL} \cdot\right.$ day $\left.^{-1}\right)$ for at least $5 \mathrm{yrs}$ and had chronic airflow limitation. The patients with chronic bronchitis were confirmed to be free of pulmonary emphysema both by selective alveolobronchograms [13] and histological examination of the autopsied lungs, and all died of chronic respiratory failure.

There were no significant differences in age, sex, smoking history, or duration of symptoms and medical history between Groups BA and $\mathrm{CB}$, except for the duration of steroid therapy. Sputum volume per day was assessed as the means of 6 days or more at times when the patients were not suffering from respiratory infection or asthma attacks whilst in the Tohoku University Hospital. Pulmonary function tests were performed 1 month to 2 years before death.

\section{Morphometry}

All lungs were fixed within $24 \mathrm{~h}$ of death. All left lungs were fixed by immersion in $10 \%$ formalin for 3 weeks or more, and used for the measurement of airways

Table 1. - Clinical and laboratory data from each subject with bronchial asthma and chronic bronchitis

\begin{tabular}{|c|c|c|c|c|c|c|c|c|c|}
\hline \multirow[t]{2}{*}{$\begin{array}{l}\mathrm{Pt} \\
\text { No. }\end{array}$} & & Sex & & $\begin{array}{c}\text { Smoking } \\
\text { habit }\end{array}$ & $\begin{array}{l}\text { Sputum } \\
\text { volume }\end{array}$ & $\mathrm{VC}$ & FEV1 & \multirow{2}{*}{$\begin{array}{l}\text { Steroid } \\
\text { dosage** }^{* *} \mathrm{mg} \cdot \text { day }^{-1}\end{array}$} & \multirow[t]{2}{*}{ Cause of death } \\
\hline & yrs & & yrs & & $\mathrm{mL} \cdot$ day $^{-1}$ & $\%$ pred & $\%$ pred & & \\
\hline
\end{tabular}

\section{Bronchial asthma patients (Group BA)}

1
2
3
4
5
6
7
8

44
52
73
69
63
63
71
37

M
M
F
F
F
F
M
M

1
10
10
6
4
12
12
1

\section{Ex-sm.}

Ex-sm.

Nonsm.

Nonsm.

Nonsm.

Nonsm.

Ex-sm.

Ex-sm.

Mean 59

7

\pm SEM \pm 5

7
\pm 2

33

Chronic bronchitis patients (Group CB)

$\begin{array}{llll}1 & 80 & \text { M } & 1 \\ 2 & 53 & \text { F } & 17 \\ 3 & 64 & \text { M } & \\ 4 & 49 & \text { M } & 28 \\ 5 & 31 & \text { M } & \\ 6 & 61 & \text { M } & 23\end{array}$

Mean $56 \quad$ M

\pm SEM \pm 7

15

\section{Control patients}

$\begin{array}{lllll}1 & 72 & \text { F } & - & \text { Nonsm. } \\ 2 & 69 & \text { M } & - & \text { Smoker } \\ 3 & 53 & \text { M } & - & \text { Nonsm. } \\ 4 & 61 & \text { M } & - & \text { Ex-sm. }\end{array}$

Ex-sm.
Nonsm.
Ex-sm.
Nonsm.
Ex-sm.
Nonsm.


Nonsm.
Smoker
Nonsm.
Ex-sm.

Nonsm.

70
100

80

50

80

80

$\pm 19$

$*$
-
-
20
80
20
40
5
33
13

$$
\begin{array}{r}
- \\
2.53 \\
2.93 \\
1.13 \\
1.54 \\
2.04 \\
5.05 \\
2.84 \\
\pm 0.57
\end{array}
$$

4.67

$4.67 \quad 122$

5.05

2.84

122
-

153

133

50

62

92

127

106

$\pm 15.1$

\subsection{9}

$$
2.81
$$

2.81
2.79

2.72

4.24

1.60

2.64

$\pm 0.39$

60
100
89
65
96
50
75
\pm 4

2.96

$-$

1.73

1.86

0.55

0.49

1.52

3.62

1.82

$\pm 0.44$

\subsection{1}

1.23

1.12

0.49

2.91

0.68

1.19

$\pm 0.36$

$63-15$

68

64

49

32

55

72

58

$\pm 5$

$46 \quad 34$

42

39

36

69

38

45

$\pm 5$
Acute asthma attack

Acute asthma attack

Acute asthma attack

Sepsis

Chronic respiratory failure Chronic respiratory failure Cytomegalovirus infection Pulmonary embolism
Chronic respiratory failure Chronic respiratory failure Chronic respiratory failure Chronic respiratory failure Chronic respiratory failure Chronic respiratory failure

Gastric cancer Acute myocardial infarction Colon cancer Acute myocardial infarction

Mean 64

\pm SEM \pm 4

\#: duration of symptoms; *: sputum volume unknown; **: dosage during the last month, calculated as prednisolone. Pt: patient; M: male; F: female; VC: vital capacity; \% pred: percentage of predicted value; FEV1: forced expiratory volume in one second; Ex-sm: ex-smoker; Nonsm: nonsmoker. 
intraluminal mucus as described previously [7]. Ten blocks from the upper and lower lobes that were macroscopically free of pneumonia were chosen at random for paraffin sectioning. Histological sections were cut $4 \mu \mathrm{m}$ thick and stained with haematoxylin and eosin and elastic (Weigert)-Masson stains. The sections stained with haematoxylin and eosin were used for cell counts in airway walls and those stained with elastic-Masson stain were used for morphometric measurements. With the elasticMasson rather than haematoxylin and eosin staining, the basement membrane could be observed more clearly and "mucus" could be distinguished from "exudate" more easily because of the fibrous structure of mucus.

Central and peripheral airways were defined as those with and without cartilage, respectively. In each case, 25 or more peripheral airways and 10 or more central airways, cut vertically in section profile, were chosen at random for morphometry of intraluminal mucus. The following morphometric measurements were performed by two observers without knowledge from which group the paraffin sections had come, and the mean value was used for data analysis. Firstly, the length of the basement membrane, inside area of the airway, and the mucus area were measured with a digitizing tablet coupled to a computer, using an image on a television monitor obtained directly from the microscope (PC-9801; NEC Corp., Tokyo, Japan; and LA-500; PIAS Co., Tokyo, Japan) [7]. To avoid any variation caused by differences of expansion among samples on immersion fixation, the luminal area was estimated by assuming the circumference of a circular airway. Luminal or internal diameter was also estimated by assuming a circular airway [7]. The area proportion of mucus was determined as the ratio of mucus to airway lumen, i.e. the ratio of the sum of mucus area to the sum of calculated luminal area in each patient was regarded as the "mucus occupying ratio" (MOR) [7].

Using the same bronchial specimens described above, the area proportion of glands (Gland\%) was determined by measuring the area of the bronchial wall excluding that with cartilage using an image of each bronchus projected onto a digitizing tablet coupled to a microcomputer. Gland\% was determined as the ratio of gland areas summed to the corresponding wall area in each subject. Simultaneously, the area proportion of mucus within goblet cells or goblet cell granules to total epithelial layer (Goblet\%) was measured both in central and peripheral airways. Twenty or more visual fields, at a magnification $\times 400$, in each airway were chosen at random for goblet cell morphometry. The epithelial area obtained in this manner occupied $20 \%$ or more and $60 \%$ or more of the total length of the epithelial layer in central and peripheral airways, respectively. Since some epithelial cell layers were observed to be detached, airways with $\geq 75 \%$ of the epithelial layers intact were chosen for morphometry, and such airways were $\geq 90 \%$ of the total airways observed in the present study. Goblet $\%$ was determined as the ratio of the sum of goblet cell intracellular mucus or granule area to that of the epithelial layer in each subject.

Some intraluminal mucus remained attached to goblet cells in the airways (fig. 1), suggesting the lack of full release or adhesion of the mucus to goblet cells, and this finding was particularly so far the airways from Group BA. In order to analyse quantitatively the adhesion of intraluminal mucus, the following parameters were adopted

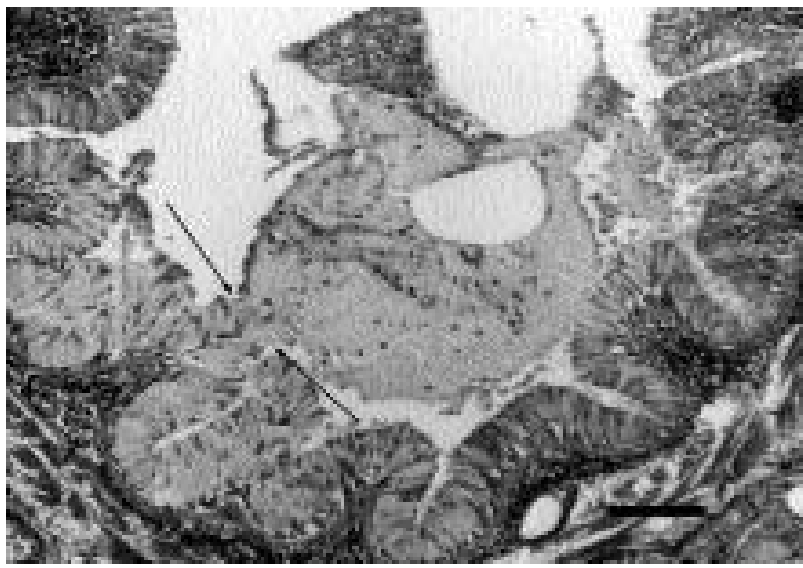

Fig. 1. - A light micrograph of peripheral airway from a female patient (aged 73 yrs) with bronchia asthma. Continuity of intraluminal mucus to goblet cells (arrows) can be seen, with marked goblet cell hyperplasia. (Elastic (Weigert)-Masson stain; internal scale bar=100 $\mu \mathrm{m})$.

for the present morphometric study. Namely, the area of intraluminal mucus continuous to goblet cells was measured and the ratio of this sum $\left(V_{\mathrm{c}}\right)$ to the sum of total intraluminal mucus ( $V$ tot) was defined as the continuous ratio in volume density $\left(V_{\mathrm{c}} / V_{\text {tot }} \%\right)$. Furthermore, the contact length of intraluminal mucus continuous to goblet cells was measured and the ratio of the sum of contact length $\left(\mathrm{Sc}_{\mathrm{c}}\right)$ to the sum of total luminal length (Stot) was defined as the continuous ratio in surface density $(\mathrm{Sc} / \mathrm{Stot} \%)$.

Various cell types in the subepithelial layer of the central airways or in the whole layer of the peripheral airways were identified and counted at $\times 400$ magnification. The number of each cell type counted was then expressed as the number per square millimetre of airway wall in a section $4 \mu \mathrm{m}$ thick. In sections taken from the central airway, various cell types were counted randomly in an area of submucosal tissue $0.25 \mathrm{~mm}$ in arc length extending between the epithelium and cartilage. The number of each cell type counted was then expressed as the number per square millimetre in the paraffin sections in each patient.

\section{Statistics}

Data are expressed as mean \pm SEM. For mean comparisons, the Student's two-tailed unpaired t-test was used for statistical analysis, and the Cochran-Cox test was used when Bartlett's test for uniformity of variance showed it to be nonuniform $[14,15]$. Significance was accepted at p-values less than 0.05 .

\section{Results}

There were no significant differences in age or smoking habit between the three groups (table 1). Furthermore, no significant differences in pulmonary function data were observed between Groups BA and CB. Although the duration of orally received glucocorticoids in Group BA (42 \pm 14 months) was much longer than that in Group CB (3.7 \pm 1 months), there was no difference in glucocorticoid dosage during the last month before death, as shown in table 1 . 
A large amount of mucus was observed in the lumen in the airways both from Groups BA and CB. Although hyperplasia and/or hypertrophy of submucosal glands and goblet cells were observed in patients both from Groups $\mathrm{BA}$ and $\mathrm{CB}$, there was a marked hyperplasia of goblet cells in the airways from subgroup BA-I. Intraluminal mucus was observed to be continuous with the goblet cells and the granules in the patients of Group BA, whilst there were no or few such findings in patients of Group $\mathrm{CB}$ or Control. A representative light micrograph of peripheral airways of patients with bronchial asthma is shown in figure 1.

No significant differences in luminal diameters of the central or peripheral airways were observed between the three groups. In central airways, the mean luminal diameter ( \pm SEM) was $3.2 \pm 0.8,3.3 \pm 0.8$ and $3.1 \pm 0.3 \mathrm{~mm}$ in Groups BA, CB and Control, respectively. In peripheral airways, the luminal diameter was $1.0 \pm 0.4,0.74 \pm 0.3$ and $0.9 \pm 0.1 \mathrm{~mm}$ in Groups BA, CB and Control, respectively.

Gland\% both in Groups BA and CB showed higher values in comparison to the Control group $(\mathrm{p}<0.01$ for each); there was no significant difference between Groups BA and CB. Gland\% values were $23 \pm 3,22 \pm 3$ and $6 \pm 2 \%$ in Groups BA, CB and Control, respectively.

Goblet $\%$ values in the central and peripheral airways of each group are shown in figure 2. Both in central and peripheral airways, Goblet\% from Groups BA and CB showed higher values compared with the Control group. However, the differences did not reach a statistical significance because of large variances (fig. 2). Furthermore, there was no significant difference in Goblet $\%$ between Groups BA and CB. In contrast, mean Goblet\% values $( \pm$ SEM) from subgroup BA-I ( $51 \pm 4$ and $50 \pm 5 \%$ in the central and peripheral airways, respectively) were significantly higher than subgroup BA-II $(9 \pm 3$ and $5 \pm 2 \% ; \mathrm{p}<0.05$ each), Group CB ( $4 \pm 2$ and $2 \pm 3 \%$; $<<0.01$ each) and Control ( $4 \pm 2$ and $2 \pm 3 \%$; $p<0.01$ each).

MOR values both from Groups BA and CB were significantly larger than those from the Control group both

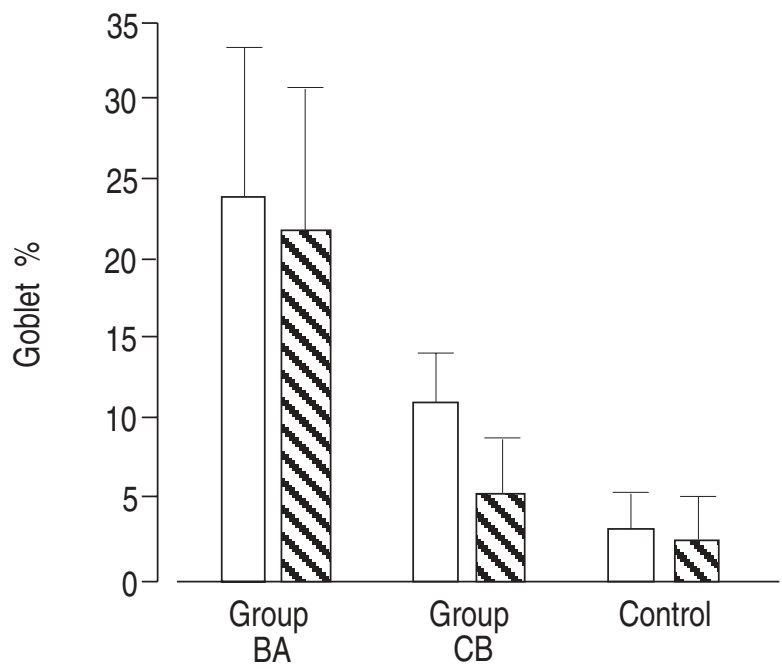

Fig. 2. - Goblet cell volume ratio (Goblet\%) of each group (mean \pm SEM) in central ( $\square$ ) and peripheral airways ( ). Both in central and peripheral airways, Goblet\% from bronchial asthma patients (Group $\mathrm{BA}, \mathrm{n}=8$ ) and chronic bronchitis patients (Group $\mathrm{CB}, \mathrm{n}=6$ ) showed higher values compared with control patients (Control, $n=4)$. However, the differences did not reach statistical significance because of large variances. Furthermore, there were no significant differences in Goblet\% between Groups BA and CB.

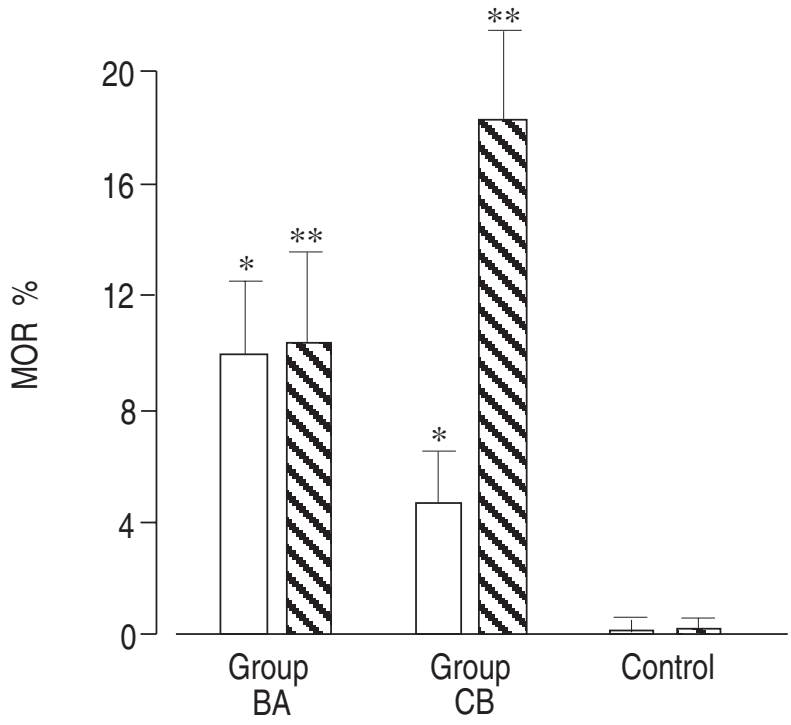

Fig. 3. - Mucus occupying ratio (MOR) of each group (mean \pm SEM) in the central ( $\square$ ) and the peripheral airways ( $)$ ). MOR values both from bronchial asthma patients (Group BA, $n=8$ ) and chronic bronchitis patients (Group $\mathrm{CB}, \mathrm{n}=6$ ) were significantly larger than those from control patients (Control, $n=4$ ) both in central and peripheral airways. However, there was no significant differences between Groups BA and CB. *: $\mathrm{p}<0.05 ; * *: \mathrm{p}<0.01$, compared to the Control group.

in central and peripheral airways, as shown in figure 3 $(\mathrm{p}<0.05$ and $\mathrm{p}<0.01$, respectively). However, there were no significant differences between Groups BA and CB.

In contrast, marked and significant increases (10-50 fold) were observed both in $V_{\mathrm{c}} / V_{\text {tot }} \%$ and $\mathrm{Sc} / \mathrm{Stot} \%$ in Group BA, compared to those of Groups CB and Control, both in central and peripheral airways, as shown in figures 4 and 5. Both $V \mathrm{c} / V$ tot $\%$ and $\mathrm{Sc} / \mathrm{Stot} \%$ in Group CB were similar to those in the Control group (figs. 4 and 5). Even when Group BA was divided into subgroups BA-I and BA-II, these differences were still statistically significant. Namely, $V_{\mathrm{c}} / V_{\text {tot }} \%$ and $\mathrm{Sc} / \mathrm{Stot} \%$ both from subgroups BA-I and BA-II were significantly higher than those from Groups $\mathrm{CB}$ and Control $\left(\mathrm{p}<0.01\right.$ in $V_{\mathrm{c}} / V_{\text {tot }} \%$ and $\mathrm{p}<0.05$ in $\mathrm{Sc} / \mathrm{Stot} \%$, both of central and peripheral airways). In the peripheral airways, $V_{\mathrm{c}} / V_{\text {tot }} \%$ was $68 \pm 3$, $39 \pm 4,5 \pm 3$ and $0.8 \pm 0.8 \%$, and $\mathrm{Sc} / \mathrm{Stot} \%$ was $10 \pm 3,6 \pm 2$, $1 \pm 1$ and $0.3 \pm 0.5 \%$ in subgroups BA-I and BA-II, and Groups $\mathrm{CB}$ and Control, respectively. In the central airways, $V \mathrm{c} / V_{\text {tot }} \%$ was $71 \pm 3,41 \pm 6,3 \pm 2$ and $2 \pm 1 \%$, and $\mathrm{Sc} /$ Stot $\%$ was $9 \pm 1,7 \pm 2,0.4 \pm 0.8$ and $0.2 \pm 0.6 \%$ in subgroups BA-I, BA-II, and Groups CB and Control, respectively.

Compared with those in the Control group (total cells: $152 \pm 40$ cells $\cdot \mathrm{mm}^{-2}$ ), there were significant increases in the total cell count in the peripheral airways both of Groups BA and CB $\left(1,342 \pm 403\right.$ cells $\cdot \mathrm{mm}^{-2}$ in Group BA and $1,403 \pm 411$ cells $\cdot \mathrm{mm}^{-2}$ in Group $\mathrm{CB} ; \mathrm{p}<0.05$ each). Significant increases in total cell count were also observed in the central airways of Groups BA $\left(403 \pm 83\right.$ cells $\left.\cdot \mathrm{mm}^{-2}\right)$ and CB $\left(228 \pm 88\right.$ cells $\left.\cdot \mathrm{mm}^{-2}\right)$ compared to the Control group $\left(103 \pm 56\right.$ cells $\left.\cdot \mathrm{mm}^{-2}\right)$. The eosinophil count in the peripheral airways of Group BA showed a significantly higher value $\left(199 \pm 68\right.$ cells $\left.\cdot \mathrm{mm}^{-2}\right)$ compared to that of Group CB $\left(10 \pm 3\right.$ cells $\left.\cdot \mathrm{mm}^{-2}\right)$ and Control $\left(2 \pm 2\right.$ cells $\left.\cdot \mathrm{mm}^{-2}\right)$ $(p<0.05$ each). Other cell counts in central or peripheral airways showed no significant differences between the three groups. 


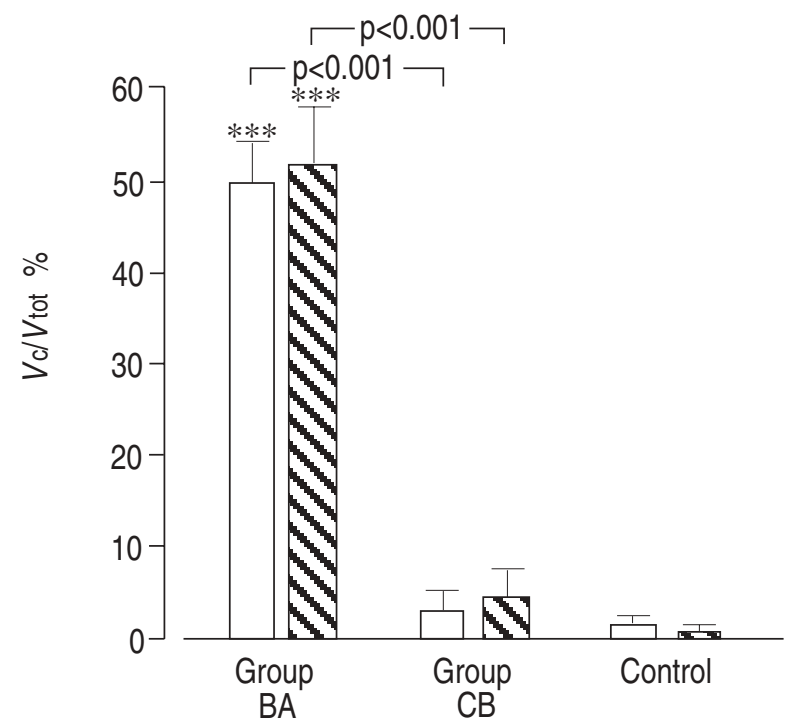

Fig. 4. - Continuous ratio (mean \pm SEM) in volume of intraluminal mucus to goblet cells $\left(V_{\mathrm{c}} / V_{\text {tot }} \%\right)$ in the central ( $\left.\square\right)$ and the peripheral ( ) airways. $V_{\mathrm{c}} / V_{\text {tot }} \%$ values from bronchial asthma patients (Group BA, n=8) were 10-50 fold higher than those both from chronic bronchitis patients (Group $\mathrm{CB}, \mathrm{n}=6$ ) and control patients (Control, $\mathrm{n}=4$ ) without any difference between Groups CB and Control. ***: $\mathrm{p}<0.001$, compared to the Control group.

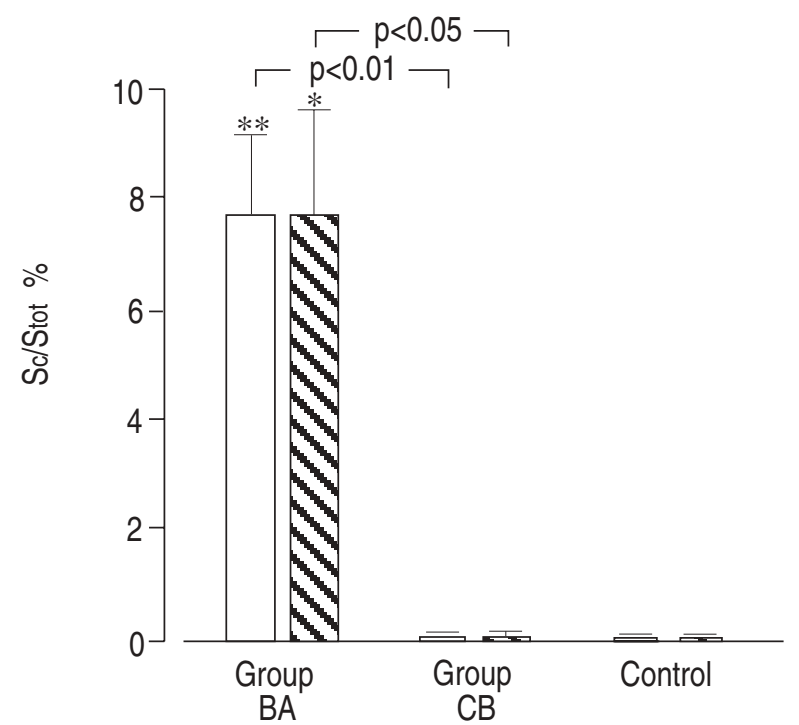

Fig. 5. - Continuous ratio (mean \pm SEM) in surface of intraluminal mucus to goblet cells $\left(\mathrm{S}_{\mathrm{c}} / \mathrm{S}\right.$ tot $\left.\%\right)$ in the central $(\square)$ and the peripheral ( ) airways. Sc/Stot\% values from bronchial asthma patients (Groups BA, $n=8$ ) were 20-40 fold higher than those both from chronic bronchitis patients (Group $\mathrm{CB}, \mathrm{n}=6$ ) and control patients (Control) without any difference between Groups $\mathrm{CB}$ and Control. *: $\mathrm{p}<0.05$; $* *$ : $\mathrm{p}<0.01$, compared to the Control group.

\section{Discussion}

Increased production of viscid mucus causing airway plugging is known to be a common pathological feature of deaths from asthma $[1-4,16]$. On the other hand, there is also heterogeneity in the asthma population, as to the cause of death and postmortem findings. For example, SobONYA [17] reported that the amount of mucous plugs, the size of submucosal glands and smooth muscles in the airways of bronchial asthma patients, not dying in status asthmaticus, was not significantly different from those of nonsmoking controls. In our previous study [18], we found a significant difference in goblet cell hyperplasia, with mucus accumulation in the peripheral airways, between patients who died of severe acute asthma attack (subgroup BA-I in the present study) and bronchial asthma patients who died of causes other than status asthmaticus (subgroup BA-II in the present study).

The difference in the airway mucus might be caused by differences in the clinical features of asthma; i.e. presence or absence of asthma attacks, severity of asthma attacks, duration of history, smoking habit, medication, treatment and cause of death [17-22].

In the present study, we included patients with both types of bronchial asthma as Group BA, resulting in no significant increase in Goblet\% of central or peripheral airways in Group BA, as a whole. Furthermore, there were no differences in Gland\%, Goblet\% or MOR between Groups BA and CB in the present study, although these values both from Groups BA and CB were significantly higher than those in the Control group.

In contrast, marked and significant differences both in $V_{\mathrm{c}} / V_{\mathrm{tot}} \%$ and $\mathrm{Sc} / \mathrm{Stot} \%$, that represent the adhesion of intraluminal mucus to the apices of goblet cells or lack of full release of mucus from goblet cells, were observed between Groups BA and CB. Namely, both $V \mathrm{c} / V$ tot $\%$ and $\mathrm{Sc} / \mathrm{Stot} \%$ in Group BA showed 10-50 fold increases compared to those of Group $\mathrm{CB}$, which were the same as those in the Control group. These differences remained significant even when Group BA was divided into two subgroups, BA-I (acute type) and BA-II (chronic type): subgroups BA-I and BA-II showed significant increases both in $V_{\mathrm{c}} / V_{\text {tot }} \%$ and $\mathrm{Sc} / \mathrm{Stot} \%$ compared to Groups $\mathrm{CB}$ and Control. These findings suggest that continuity or adhesion of intraluminal mucus to goblet cells is peculiar to the airways of patients with bronchial asthma. To our knowledge, this is the first report showing a marked continuity of goblet cells to intraluminal mucus in the airways of patients with bronchial asthma. It is possible that altered mucin secretion in goblet cells of asthmatic airways contributes to this condition, since Group CB did not show any significant increases in $V_{\mathrm{c}} / V_{\text {tot }} \%$ or $\mathrm{Sc} / \mathrm{Stot} \%$, compared to the Control group in spite of increased luminal mucin (MOR) in the airways.

There has been some controversy concerning airway goblet cell secretion. It has been shown [23] that goblet cell mucin secretion is not under any pharmacological control [23]; and some investigators have indicated that airway goblet cells are unresponsive to $\beta$-adrenergic and cholinergic stimuli $[24,25]$. In contrast, leukotriene $D_{4}$ is reported to induce secretion of mucus from airway goblet cells in guinea-pig in vivo [26]. Cultured goblet cells secrete mucins continuously, probably by a constitutive pathway [27], a pathway similar to intestinal goblet cells [28]. However, recent studies [29-32] have indicated that human neutrophil elastase and exogenous adenosine triphosphate (ATP) can release mucins from surface goblet cells through degranulation or exocytosis. Thus, airway goblet cell mucins seem to be secreted by two secretory pathways: a constitutive (or vesicular) pathway and a granular pathway [33].

Although it is still not known which pathway is the main contributor to the formation of mucous-plugging or the connection of goblet cells to luminal mucus in the 
airways of patients with bronchial asthma, our hypothesis is as follows. During mucin secretion, the storage granules and/or vesicles are fused with plasma membrane in airway goblet cells. Some mucins are released, whereas other mucins remain attached to the outer plasma membrane [33]. The cell surface mucins can be released by proteases, such as those released by neutrophils during airway inflammation or possibly by some endogenous proteinases under normal physiological conditions [33]. The mechanism by which mucins are anchored to the plasma membrane remains to be investigated. However, we speculate that the mucins attached to goblet cell membranes are markedly increased and/or that the mechanism for the release of the attached mucin is in some way disturbed in the airways of patients with bronchial asthma. This is not the case in the airways of patients with chronic bronchitis that show neutrophil infiltration. Large numbers of eosinophils and few neutrophils in the airways of patients with bronchial asthma may be contributing to the lack of release of cell surface-attached mucins, and thereby to the continuity of luminal mucus and goblet cells.

Other differences exist between secretions from submucosal glands and those from goblet cells, i.e. it has been suggested that goblet cells secrete a more acidic mucous glycoprotein than do submucosal glands [34]. Sputum samples collected during an asthma attack have been shown to be more acidic, compared with those not under going an attack and with other patients with respiratory diseases [35]. Holma et al. [36] have reported that ciliary inhibition is seen in bovine trachea at low $\mathrm{pH}$, especially near 6.5. This acidic nature of mucus may contribute to the formation and/or the connection of goblet cells to intraluminal mucus.

In conclusion, we suggest that the continuity of surface goblet cell granules and intraluminal mucus is peculiar to the airways of patients with bronchial asthma, contributing to the formation of mucous-plugging and resulting in death.

Acknowledgements: The authors gratefully acknowledge K. Suzuki for technical assistance and B. Bell for reading the manuscript.

\section{References}

1. Dunnill MS. The pathology of asthma with special reference to changes in the bronchial mucosa. J Clin Pathol 1960; 13: 27-33.

2. Messer JW, Peters GA, Bennett WA. Cause of death and pathologic findings in 304 cases of bronchial asthma. Dis Chest 1960; 38: 616-624.

3. Houston JC, De Navasquez S, Trounce JR. A clinical and pathological study of fatal cases of status asthmaticus. Thorax 1953; 8: 207-213.

4. Saetta M, Stefano AD, Rosina C, Thiene G, Fabbri LM. Quantitative structural analysis of peripheral airways and arteries in sudden fatal asthma. Am Rev Respir Dis 1991; 143: $138-143$

5. Glynn AA, Michaels L. Bronchial biopsy in chronic bronchitis and asthma. Thorax 1960; 15: 142-153.

6. Dunnill MS, Massarella GR, Anderson JA. A comparison of the quantitative anatomy of the bronchi in normal subjects, in status asthmaticus, in chronic bronchitis and in emphysema. Thorax 1969; 24: 176-179.

7. Aikawa T, Shimura S, Sasaki H, Takishima T, Yaegashi $\mathrm{H}$, Takahashi T. Morphometric analysis of intraluminal mucus in airways in chronic obstructive pulmonary diseases. Am Rev Respir Dis 1989; 140: 477-482.

8. Cosio M, Ghezzo H, Hogg JC, et al. The relations between structural changes in small airways and pulmonary function tests. N Engl J Med 1977; 298: 1277-1281.

9. American Thoracic Society. Chronic bronchitis, asthma and pulmonary emphysema: a statement by the committee on diagnostic standards for nontuberculous respiratory diseases. Am Rev Respir Dis 1962; 85: 762-768.

10. Rackemann FM. A working classification of asthma. Am J Med 1947; 3: 601-606.

11. British Medical Research Council. Definition and classification of chronic bronchitis for clinical and epidemological study purposes: a report of the Medical Research Council by their committee on the etiology of chronic bronchitis. Lancet 1965; i: 775-779.

12. Homma H, Yamanaka A, Tanimoto S, et al. Diffuse panbronchiolitis: a disease of transitional zone of the lung. Chest 1983; 83: 63-69.

13. Sasaki H, Okayama H, Aikawa T, et al. Central and peripheral airways as determinants of ventilatory function in patients with chronic bronchitis, emphysema and bronchial asthma. Am Rev Respir Dis 1986; 134: 11821189.

14. Cochran WG, Cox GM. In: Experimental Designs. New York, John Wiley \& Son Inc., 1950.

15. Feinstein AR. Statistics versus science in the design of experiments. In: Clinical Biostatistics. St. Louis, The C.V. Mosby Co., 1977; pp. 17-27.

16. Cardell BS, Pearson RSB. Death in asthmatics. Thorax 1959; 14: 341-352.

17. Sobonya RE. Quantitative structural alterations in longstanding allergic asthma. Am Rev Respir Dis 1984; 130: 289-292.

18. Aikawa T, Shimura S, Sasaki H, Ebina M, Takishima T. Marked goblet cell hyperplasia with mucus accumulation in the airways who died of severe acute asthma attack. Chest 1992; 101: 916-921.

19. Reid LM. The presence or absence of bronchial mucus in fatal asthma. J Allergy Clin Immunol 1987; 80: 415-416.

20. Lundgren JD, Kaliner M, Logun C, Shelhamer JH. Dexamethasone reduces rat tracheal goblet cell hyperplasia produced by human neutrophil products. Exp Lung Res 1988; 14: 853-863.

21. Rogers DF, Jeffery PK. Inhibition of cigarette smokeinduced airway secretory cell hyperplasia by indomethacin, dexamethasone, prednisolone or hydrocortisone in the rat. Exp Lung Res 1986; 10: 285-298.

22. Sturgess J, Reid L. The effect of isoprenaline and pilocarpine on (a) bronchial mucus-secretory tissue and (b) pancreas, salivary, liver and spleen. Br J Exp Pathol 1973; 54: 388-403.

23. Kim KC, Nassiri J, Brody JS. Mechanisms of airway goblet cell mucin release: studies with cultured tracheal surface epithelial cells. Am J Respir Cell Mol Biol 1989; 1: 137-143.

24. Basbaum C, Carlson D, Davidson E, Verdugo P, Gail DB. Cellular mechanisms of airway secretion. Am Rev Respir Dis 1988; 137: 479-485.

25. Gail DB, Lenfant CJM. Cells of the lung: biology and clinical implication. Am Rev Respir Dis 1983; 127: 366-387. 
26. Hoffstein ST, Malo PE, Bugelski P, Wheeldon EB. Leukotriene $\mathrm{D}_{4}\left(\mathrm{LTD}_{4}\right)$ induces mucus secretion from goblet cells in the guinea-pig respiratory epithelium. Exp Lung Res 1990; 16: 711-725.

27. Wasano K, Kim KC, Niles RM, Brody JS. Membrane differentiation markers of airway epithelial secretory cells. J Histochem Cytochem 1988; 36: 167-178.

28. Neutra MR, O'Malley LJ, Specian RD. Regulation of intestinal goblet cell secretion. II. A survey of potential secretagogues. Am J Physiol 1982; 242: G380-G387.

29. Breuer P, Christensen TG, Niles PM, Stone PJ, Snider GL. Human neutrophil elastase causes glycoconjugate release from the epithelial cell surface of hamster trachea in organ culture. Am Rev Respir Dis 1989; 139: 779-782.

30. Davis CW, Lowell ML, Lethem M, Scott MV. Goblet cell degranulation in isolated canine tracheal epithelium: response to exogenous ATP, ADP and adenosine. Am J Physiol 1992; 26: C1313-C1323.

31. Breuer P, Christensen TG, Lucey EC, Stone PJ, Snider GL. An ultrastructural morphometric analysis of elas- tase-treated hamster bronchi shows discharge followed by progressive accumulation of secretory granules. Am Rev Respir Dis 1987; 136: 698-703.

32. Kim KC, Wasano K, Niles RM, Schuster JE, Stone PJ, Brody JS. Human neutrophil elastase releases cell surface mucins from primary cultures of hamster tracheal epithelial cells. Proc Natl Acad Sci USA 1987; 84: 9304-9308.

33. Kim KC. Epithelial goblet cell secretion. In: T. Takishima, S. Shimura eds. Airway Secretion. New York, Marcel Dekker Inc., 1994; pp. 433-449.

34. Stahl GH, Ellis DB. Biosynthesis of respiratory tract mucins: a comparison of canine epithelial goblet cell and submucosal gland secretions. Biochem J 1973; 136: 845-850.

35. Shimura S, Sasaki T, Sasaki H, Takishima T. Chemical properties of bronchorrhea sputum in bronchial asthma. Chest 1988; 94: 1211-1215.

36. Holma B, Lindegren M, Andersen JM. pH effects on ciliomotility and morphology of respiratory mucosa. Arch Environ Health 1977; 32: 216-226. 